Check for updates

Cite this: RSC Adv., 2017, 7, 46520

Received 21st August 2017

Accepted 21st September 2017

DOI: $10.1039 / c 7 r a 09243 a$

rsc.li/rsc-advances

\section{Synthesis and characterization of metal-organic frameworks fabricated by microwave-assisted ball milling for adsorptive removal of Congo red from aqueous solutions}

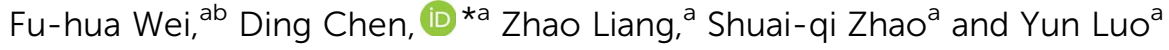

In this study, four metal-organic frameworks (MOFs) were prepared using a simple, low-cost, and highefficiency technique utilizing simple carboxylic acids (1,3,5-benzenetricarboxylic acid and terephthalic acid) and metal salts (copper(॥) acetate tetrahydrate and cobalt(॥) acetate tetrahydrate) and microwaveassisted ball milling. The MOFs were characterized by infrared spectrometry, X-ray diffraction, scanning electron microscopy, and thermogravimetry. They were investigated for use as adsorbents for the adsorption of Congo red (CR) from aqueous solutions. The results showed that the adsorption capacity of MOF-2-synthesized from trimesic acid and cobalt(I) acetate tetrahydrate-was the highest, reaching $85.54 \%$ after $300 \mathrm{~min}$. Electrostatic and $\pi-\pi$ stacking interactions are thought to play an important role in the adsorption of CR onto the MOFs. This MOF material reported in this work demonstrates a superior dye adsorption capacity when compared to other adsorbents.
\end{abstract}

\section{Introduction}

Porous materials have come to constitute one of the studied focus areas of chemists, materials scientists, and physicists. Metal-organic frameworks (MOFs), a new class of porous materials, have quickly progressed into a fruitful research field. ${ }^{1-3}$ In the past twenty years, MOFs have garnered considerable interest as a novel type of functional porous material and have been tested for applications involving energy storage, ${ }^{\mathbf{4 , 5}}$ adsorption and separation, ${ }^{\mathbf{6}, 7}$ catalysis, ${ }^{\mathbf{8}, 9}$ drug delivery, ${ }^{10,11} \mathrm{CO}_{2}$ capture, ${ }^{12,13}$ chemical sensors, ${ }^{14}$ and others. $^{\mathbf{1 5 , 1 6}}$ Since their first report, many studies have described the use of MOFs for filtration of wastewater. For instance, in hexavalent chromium reduction, various MOFs including MIL-125(Ti), ${ }^{17}$ MIL-53(Fe), ${ }^{18}$ and $\mathrm{Zn}(\mathrm{Ce})-\mathrm{MOFs}^{19}$ have been used. MOFs, namely MOF- $235^{20}$ and $\mathrm{g}-\mathrm{C}_{3} \mathrm{~N}_{4} / \mathrm{MIL}-$ 125(Ti), ${ }^{21}$ have also been utilized for the degradation of organic dyes in wastewater. MOFs are usually synthesized by solvothermal, microwave-assisted, and mechanochemical processes.

Mechanochemical processes have been long established and their usefulness stems from the capacity to rapidly and quantitatively promote solid-phase reactions using only ball milling or liquid-assisted grinding. In traditional chemical

${ }^{a}$ College of Materials Science and Engineering, Hunan University, Hunan, Changsha 410082, PR China.E-mail: ma97chen@hotmail.com

${ }^{b}$ College of Chemistry and Chemical Engineering, Anshun University, Guizhou, Anshun 561000, PR China synthesis, the solvent often plays a key role in solvation, transportation, and energy dispersion of chemicals. Energy and mass transport may be reduced in solvent-free reactions. The efficient mixing process under ball milling can overcome this drawback, enabling reactions between solids to take place even under solvent-free conditions. ${ }^{22-24}$ In mechanochemical procedures, the energy needed for the activation of chemical reactions is usually provided by mechanical force, similarly to how it is provided by light, heat, and electrical potential in photochemistry, thermochemistry, and electrochemistry, respectively. Developments concerning mechanochemical procedures have mostly taken place in the last two decades, and usually focused on their application in synthetic organic chemistry. Recent research efforts have involved exploring the concept of mechanochemistry to obtain advanced materials with a wide range of applications and uses. $^{25-28}$ In addition to classical organic synthesis, therefore, mechanochemistry has been applied to the synthesis of MOFs, ${ }^{29-31}$ metal complexes, ${ }^{25,26}$ and hydrogen storage materials. $^{32}$

Organic dyes are pollutants, and can include chemicals that are toxic or carcinogenic to mammals and other living organisms. ${ }^{3,34}$ Dye molecules are often stable and resistant to biodegradation under normal conditions as a result of their complex molecular structures. Therefore, removal of dyes from wastewater by biological or chemical degradation methods can be very challenging. Nevertheless, several groups have explored the possibility of applying polymeric and MOF materials for the removal or degradation of various dye 
species. For example, Wang et al. have reported four cobalt(II) coordination polymers for the degradative removal of an azo dye Congo red (CR). ${ }^{35}$ Degradation efficiency of complex 1 or 2 on Congo red ended up to 89 or $98 \%$ after $130 \mathrm{~min}$, respectively. Complex 3 or 4 was introduced into the system, only about 56 or $52 \%$ of the dye was decolored, respectively. $\mathrm{Hu}$ et al. have synthesized a MOF for use in the degradative removal of methyl orange. ${ }^{36}$ Degradation efficiency can reach $76.1 \%$ for 1 within $30 \mathrm{~min}$ and reaching up to $92.8 \%$ for 1 in 120 min; Cui et al. have prepared two copper(I) cyanide coordination polymers and utilized them for the degradation and removal of methylene blue. ${ }^{37}$ Photodegradation efficiency (using CP 1 is $90.8 \%$ and using CP 2 is $87.2 \%$ ) for the degradation of methylene blue (MB) under UV light irradiation. Masoomi et al. have synthesized TMU-5 and TMU-6 materials for the degradation and removal of RhB. ${ }^{38}$ Zhao et al. have reported the synthesis of $\mathrm{Ni}-\mathrm{MOF} / \mathrm{GO}$, which was applied to the degradation and removal of $\mathrm{CR} .^{39}$ The adsorption capacity of graphene oxide/metal-organic frameworks (GO/MOFs) for CR reached $2489 \mathrm{mg} \mathrm{g}^{-1}$. Racles et al. have synthesized a siloxane-based MOF and applied it to the degradative removal of $\mathrm{CR}^{40}$ etc.

Microwave-assisted ball milling-first reported by our laboratory-is based on a solid-liquid ball milling approach where a ball milling machine is placed in a microwave oven. ${ }^{41-43}$ This method improves the speed of chemical reactions and alter their routes. ${ }^{\mathbf{4 4}-47}$ Herein, four MOFs were obtained by microwave-assisted ball milling from trimesic acid, terephthalic acid, $\mathrm{Cu}\left(\mathrm{CH}_{3} \mathrm{COO}\right)_{2} \cdot \mathrm{H}_{2} \mathrm{O}$, and $\mathrm{Co}\left(\mathrm{CH}_{3} \mathrm{COO}\right)_{2} \cdot 4 \mathrm{H}_{2} \mathrm{O}$ as the starting materials, and applied successfully for the reduction of aqueous CR.

\section{Results and discussion}

\section{Preparation of MOFs}

Crystals are most often isolated under microwave-assisted heating because of the fast kinetics of crystal growth and nucleation. Therefore, the greatest challenge with microwave heating is restricting the crystallite size. Crystals of large sizes are usually more difficult to acquire under microwave heating than in typical solvothermal processes. In this work, acid is produced using a post-treatment process according to the following reaction:

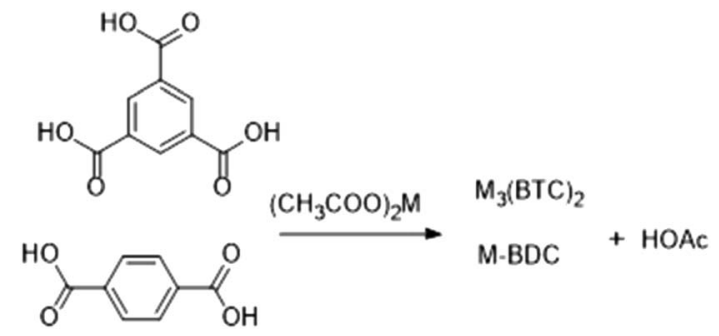

Under the combined action of microwave irradiation and ball milling that provides mechanical energy, trimesic acid is easily deionized to form a $\pi_{3}^{5}$ negative ion in aqueous solutions. $\mathrm{Cu}$ and Co could each lose two electrons from their s orbital, leading to an empty orbital in each case. The trimesic acid anion can provide electrons to the metal ions and release acetic acid molecules, which react with the metal ions in a proportion of $1: 1.5$ or $1: 1$. The specific reaction mechanism has been previously reported. ${ }^{48}$ The reaction mechanism for the reaction of a metal salt with $\mathrm{H}_{3}$ BTC or $\mathrm{H}_{2}$ BDC can be described as follows:<smiles>CC(C)(C)C(=O)c1ccc(C(=O)O)cc1C(=O)O</smiles><smiles></smiles><smiles>COC(=O)c1cc(C(=O)O)cc(C(=O)ONOC(=O)c2cc(C(=O)O)cc(C(=O)O)c2)c1</smiles><smiles>CCN(CCCOC(=O)c1ccc(C(=O)OC(C)=O)cc1)C(C)=O</smiles><smiles>O=C([O-])c1ccc(C(=O)O[M]OC(=O)c2ccc(C(=O)O[W])cc2)cc1</smiles> 
Preparation of the MOFs was fast and achieved without the need for an organic solvent, unlike the previously reported preparation of MOFs shown in Table 1.

\section{Structure characterization}

Fourier-transform infrared spectroscopy. Fourier-transform infrared (FTIR) spectra of the MOFs were acquired using $\mathrm{KBr}$ pellets in the $500-3000 \mathrm{~cm}^{-1}$ region and are shown in Fig. 1 . The spectra displayed the peaks characteristic for the main functional groups of MOFs-1-4 at $1558 \mathrm{~cm}^{-1}, 1400 \mathrm{~cm}^{-1}$; $1570 \mathrm{~cm}^{-1}, 1373 \mathrm{~cm}^{-1} ; 1558 \mathrm{~cm}^{-1}, 1398 \mathrm{~cm}^{-1}$; and $1558 \mathrm{~cm}^{-1}$, $1361 \mathrm{~cm}^{-1}$, respectively. The prepared materials displayed no strong carbonyl peak at $\sim 1710 \mathrm{~cm}^{-1}$. This observation was mainly attributed to the fact that the carboxyl anions can form $\pi_{3}^{5}$ after the formation of the carboxylate, and the two resulting oxygen atoms on the carboxyl group tend to be equivalent, thus leading to an delocalized electronic cloud and appearance of characteristic carboxylate peaks in the ranges of 1610$1550 \mathrm{~cm}^{-1}$ and $1420-1300 \mathrm{~cm}^{-1} \cdot{ }^{49}$ Thus, these results confirmed that the metal salts and organic acids formed the target coordination compounds.

X-ray diffraction. The synthesized MOF structures were elucidated by powder X-ray diffraction (XRD). The main peak observed in the XRD pattern of MOF-1 matched well with literature data. ${ }^{50}$ The XRD patterns for the various MOFs are shown in Fig. 2. It can be seen that MOFs-1-4 exhibited main diffraction peaks at $2 \theta$ values of $20.2^{\circ}, 11.6^{\circ}, 9.5^{\circ} ; 29.2^{\circ}, 27.8^{\circ}$, $8.7^{\circ} ; 27.8^{\circ}, 18.9^{\circ}, 11.7^{\circ}$; and $27.9^{\circ}, 14.3^{\circ}, 9.7^{\circ}$, respectively. The patterns showed fairly high intensities, indicating the high crystallinity of the samples.

Scanning electron microscopy. The particle size and morphology of each MOF was observed by scanning electron microscopy (SEM), as shown in Fig. 3. The SEM images demonstrated the presence of MOF crystals with high dispersity and unusual particle morphology. The morphology of MOF-1 was quite similar to that reported previously. ${ }^{50,51}$ Currently,

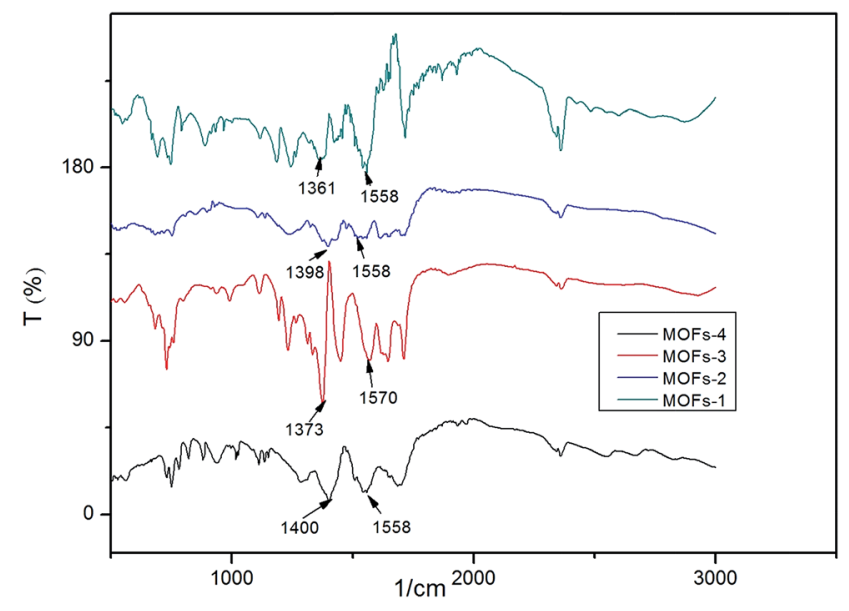

Fig. 1 FTIR spectra for MOFs.

the molecular interactions of the organic ligands will be weak or even absent, and the deprotonation of the organic ligands can be enhanced in order to promote the growth of crystals in aqueous solution.

Thermogravimetric analysis. Thermogravimetric analysis (TGA) was performed to determine the composition of this membrane (Fig. 4), demonstrating that metal salts of the same type exhibited similar thermal decomposition temperatures in Ar atmosphere. The TG curves showed three different areas for each MOF. For MOF-1: the first mass loss (8.3\%) area between $106{ }^{\circ} \mathrm{C}$ and $189{ }^{\circ} \mathrm{C}$ was attributed to the evaporation of water molecules from the surface of the sample; the area between $189{ }^{\circ} \mathrm{C}$ and $310{ }^{\circ} \mathrm{C}$, exhibiting slow mass loss of $7.6 \%$, was related to the loss of water from the MOF together with oxidation $^{48}$ of $\mathrm{Cu}^{2+}$; and the third region starting at $310{ }^{\circ} \mathrm{C}$ was attributed to the collapse of the MOF and fracturing of the organic linkers, thus indicated that the MOF is thermally stable up to $310^{\circ} \mathrm{C}$. The loss of mass was completed by $310{ }^{\circ} \mathrm{C}$ and the

Table 1 Comparison of different procedures for preparation of MOFs

\begin{tabular}{|c|c|c|c|c|c|c|}
\hline MOF & Reagent & Solvent & $\begin{array}{l}\text { Temperature } \\
\left({ }^{\circ} \mathrm{C}\right)\end{array}$ & $\begin{array}{l}\text { Time } \\
\text { (h) }\end{array}$ & $\begin{array}{l}\text { BET } \\
\left(\mathrm{m}^{2} \mathrm{~g}^{-1}\right)\end{array}$ & Ref. \\
\hline MOFs-1 & $\mathrm{H}_{3} \mathrm{BTC}, \mathrm{Cu}(\mathrm{OAc})_{2} \cdot \mathrm{H}_{2} \mathrm{O}$ & $\mathrm{H}_{2} \mathrm{O}$ & Room temperature & 0.5 & 32.0708 & This work \\
\hline MOFs-2 & $\mathrm{H}_{3} \mathrm{BTC}, \mathrm{Co}(\mathrm{OAc})_{2} \cdot 4 \mathrm{H}_{2} \mathrm{O}$ & & & & 7.7682 & \\
\hline MOFs-3 & $\mathrm{H}_{2} \mathrm{BDC}, \mathrm{Cu}(\mathrm{OAc})_{2} \cdot \mathrm{H}_{2} \mathrm{O}$ & & & & 82.991 & \\
\hline MOFs-4 & $\mathrm{H}_{2} \mathrm{BDC}, \mathrm{Co}(\mathrm{OAc})_{2} \cdot 4 \mathrm{H}_{2} \mathrm{O}$ & & & & 0.9113 & \\
\hline MIL-125(Ti) & $\mathrm{H}_{2} \mathrm{BDC}, \mathrm{Ti}\left(\mathrm{OC}_{4} \mathrm{H}_{9}\right)_{4}$ & $\mathrm{CH}_{3} \mathrm{OH}, \mathrm{DMF}$ & 150 & 48 & 1548.3 & 17 \\
\hline $\mathrm{NH}_{2}$-MIL-125(Ti) & $\mathrm{NH}_{2}-\mathrm{BDC}, \mathrm{Ti}\left(\mathrm{OC}_{4} \mathrm{H}_{9}\right)_{4}$ & $\mathrm{CH}_{3} \mathrm{OH}, \mathrm{DMF}$ & 150 & 48 & 1343.9 & 17 \\
\hline MIL-53(Fe) & $\mathrm{H}_{2} \mathrm{BDC}, \mathrm{FeCl}_{3} \cdot 6 \mathrm{H}_{2} \mathrm{O}$ & DMF & 150 & 15 & - & 18 \\
\hline HUT-091 & $\mathrm{H}_{3} \mathrm{BTC}, \mathrm{Ce}\left(\mathrm{NO}_{3}\right)_{3} \cdot 6 \mathrm{H}_{2} \mathrm{O}$ & & 170 & 240 & - & 19 \\
\hline MIL-68(In) & $\mathrm{H}_{2} \mathrm{BDC}, \mathrm{In}\left(\mathrm{NO}_{3}\right)_{3} \cdot x \mathrm{H}_{2} \mathrm{O}$ & DMF & 100 & 48 & 681.4 & 55 \\
\hline$[\mathrm{Co}(\mathrm{L} 1)(\mathrm{bpdc})]_{n}$ & $\begin{array}{l}\text { 1,4-Bis(5,6-dimethylbenzimidazol-1- } \\
\text { ylmethyl)benzene, } \mathrm{H}_{2} \text { bpdc, } \mathrm{CoCl}_{2} \cdot 6 \mathrm{H}_{2} \mathrm{O}\end{array}$ & $\mathrm{H}_{2} \mathrm{O}$ & 140 & 36 & 0.912 & 35 \\
\hline$\left\{[\mathrm{Co}(\mathrm{L} 1)(\mathrm{npht})] \cdot 0.5 \mathrm{H}_{2} \mathrm{O}\right\}_{n}$ & $\begin{array}{l}\text { 1,4-Bis(5,6-dimethylbenzimidazol-1- } \\
\text { ylmethyl)benzene, } \mathrm{H}_{2} \mathrm{npht}, \mathrm{CoCl}_{2} \cdot 6 \mathrm{H}_{2} \mathrm{O}\end{array}$ & & & & 0.783 & \\
\hline$[\mathrm{Co}(\mathrm{L} 2)(\mathrm{bpdc})]_{n}$ & $\begin{array}{l}\text { 1,3-Bis(5,6-dimethylbenzimidazol-1- } \\
\text { ylmethyl)benzene, } \mathrm{H}_{2} \text { bpdc, } \mathrm{CoCl}_{2} \cdot 6 \mathrm{H}_{2} \mathrm{O}\end{array}$ & & & & 0.852 & \\
\hline$\left[\mathrm{Co}(\mathrm{L} 3)(\mathrm{bpdc})\left(\mathrm{H}_{2} \mathrm{O}\right)\right]_{n}$ & $\begin{array}{l}\text { 1, } 1^{\prime} \text {-Bis }(5,6 \text {-dimethylbenzimidazole)methane, } \\
\mathrm{H}_{2} \text { bpdc, } \mathrm{CoCl}_{2} \cdot 6 \mathrm{H}_{2} \mathrm{O}\end{array}$ & & & & 0.813 & \\
\hline
\end{tabular}




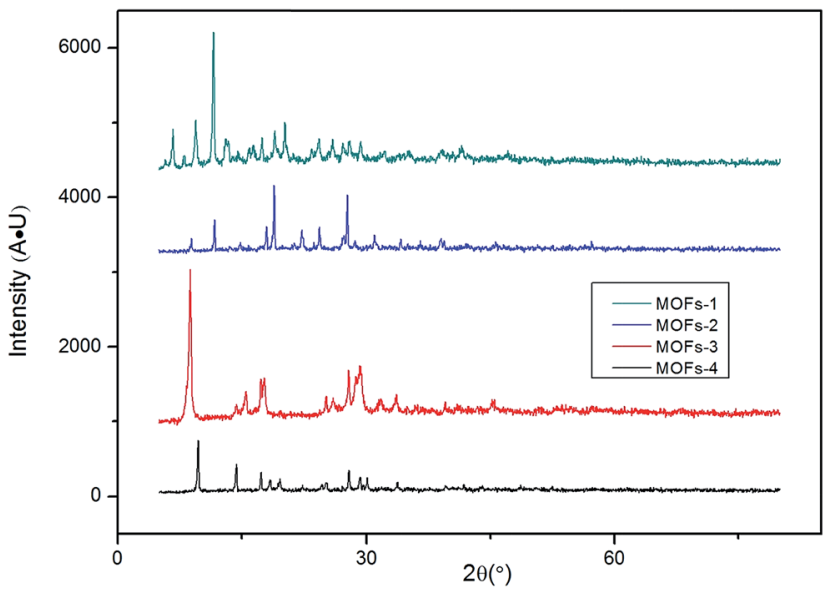

Fig. 2 XRD patterns for MOFs.

mass subsequently remained stable up to $800{ }^{\circ} \mathrm{C}$. The residue measured at this temperature represented $35.03 \%$ of the original mass.

For MOF-2: the first mass loss $(16.5 \%)$ area between $100{ }^{\circ} \mathrm{C}$ and $223{ }^{\circ} \mathrm{C}$ indicated the loss of moisture; the area between $223{ }^{\circ} \mathrm{C}$ and $366^{\circ} \mathrm{C}$ with a slow loss of $3.3 \%$ mass was related to the oxidation of $\mathrm{Co}^{2+}$; the third region starting at $366{ }^{\circ} \mathrm{C}$ represented again the temperature at which the structure of the MOF collapsed and the organic linker was fractured. The loss of mass was deemed as complete at $366^{\circ} \mathrm{C}$, after which the MOF remained stable up to $800{ }^{\circ} \mathrm{C}$. The residue measured at this temperature was $33.17 \%$ of the original mass.

For MOF-3: the first mass loss (7.63\%) area between $74{ }^{\circ} \mathrm{C}$ and $330{ }^{\circ} \mathrm{C}$ indicated the loss of moisture and oxidation ${ }^{52}$ of $\mathrm{Cu}^{2+}$; the third region started at $330^{\circ} \mathrm{C}$, a temperature at which the structure of the MOF collapsed and the organic linker was fractured. This loss of mass was completed by $330{ }^{\circ} \mathrm{C}$ and the MOF was stable up to $800{ }^{\circ} \mathrm{C}$. The final residue was $43.5 \%$ of the original mass.

For MOF-4: the first mass loss $(7 \%)$ area between $152{ }^{\circ} \mathrm{C}$ and $229{ }^{\circ} \mathrm{C}$ indicated the loss of moisture; the area between $229^{\circ} \mathrm{C}$ and $346{ }^{\circ} \mathrm{C}$ with a slow mass loss of $5.6 \%$ was related to the loss of water from the MOF together with the oxidation of $\mathrm{Co}^{2+}$; the third region started at $346{ }^{\circ} \mathrm{C}$, a temperature at which the structure of the MOF collapsed and the organic linker was fractured. This loss of mass was completed by $346{ }^{\circ} \mathrm{C}$ and the MOF remained stable up to $800{ }^{\circ} \mathrm{C}$. The final residue represented $29.7 \%$ of the original mass.

\section{Removal of Congo red}

The specific surface areas of MOFs-1-4 were determined to be $32.0708 \mathrm{~m}^{2} \mathrm{~g}^{-1}, 7.7682 \mathrm{~m}^{2} \mathrm{~g}^{-1}, 82.9910 \mathrm{~m}^{2} \mathrm{~g}^{-1}$, and $0.9113 \mathrm{~m}^{2} \mathrm{~g}^{-1}$, respectively, as shown Table 1 , using the nitrogen adsorption isotherms. The adsorption performance of the four MOFs toward CR was studied. Fig. 5 shows the adsorbed quantities $\left(q_{t}\right)$ of CR on the MOFs as a function of time $t$, as determined using the following equations:

$$
q_{t}=\left(C_{0}-C_{t}\right) V / m
$$

$$
q_{\mathrm{e}}=\left(C_{0}-C_{\mathrm{e}}\right) V / m
$$

where $q_{t}$ and $q_{\mathrm{e}}$ are the amounts $\left(\mathrm{mg} \mathrm{g}^{-1}\right)$ of dye adsorbed on the adsorbents at time $t$ and equilibrium, respectively; $C_{0}, C_{t}$, and $C_{\mathrm{e}}$ are the liquid-phase concentrations $\left(\mathrm{mg} \mathrm{L}^{-1}\right)$ of $\mathrm{CR}$ initially, at time $t$, and at equilibrium, respectively; and $m(\mathrm{~g})$ and $V(\mathrm{~L})$ represent the quality of the adsorbent and the volume (L) of CR solution, respectively.

As seen in Fig. 5, initially, the adsorption capacities of the MOFs for CR increased rapidly and then gradually decreased until the adsorption equilibria were attained upon prolonged contact. The $q_{\mathrm{e}}$ values of the four MOFs for CR were quite different. Specifically, these values were 129.95, 120.15, 77.05, and $64.56 \mathrm{mg} \mathrm{g}^{-1}$ for MOF-2, MOF-1, MOF-3, and MOF-4, respectively. Clearly, the different results were arising due to the introduction of different organic ligands and metal ions. The electron energy arrangements of $\mathrm{Cu}$ and Co are $3 \mathrm{~d}^{9} 4 \mathrm{~s}^{2}$ and $3 \mathrm{~d}^{7} 4 \mathrm{~s}^{2}$, respectively. For these metals, the loss of two electrons from their s orbital gives rise to an empty orbital in each case. Different metal ions and different organic ligands have different spatial structures, resulting in different adsorption results.

It is possible that the original concentrations of CR were sufficiently high to provide the driving force to surpass the resistance of mass transfer between the liquidoid and the solidoid. ${ }^{53}$

The adsorption isotherms were acquired after adsorption for $5 \mathrm{~h}$. The adsorption capacities of the MOFs under investigation in the removal of CR were in the following order: MOF-4 > MOF$3>$ MOF-2 > MOF-1 (as shown in Fig. 6). The maximum adsorption of CR was $85.45 \%$ after $300 \mathrm{~min}$, determined for MOF-2 in natural light.

\section{Kinetics for the adsorption of Congo red by MOFs}

The adsorption capacity was obtained to study the kinetics of adsorption of CR by the prepared MOFs. The adsorption model that describes the adsorption of a solute onto a solid surface can be expressed as:

$$
\frac{\mathrm{d} q}{\mathrm{~d} t}=k_{1}\left(q_{\mathrm{e}}-q_{t}\right)
$$

where $k_{1}$ is the apparent pseudo-first-order rate constant $\left(\min ^{-1}\right), q_{t}$ is the adsorption capacity at time $t\left(\mathrm{mg} \mathrm{g}^{-1}\right)$, and $q_{\mathrm{e}}$ is the adsorption capacity at equilibrium $\left(\mathrm{mg} \mathrm{g}^{-1}\right)$.

The applicability of the pseudo-first-order kinetic model to the adsorption of CR by MOFs was tested by fitting of the experimental data to the model via the application of the least squares regression analysis (as shown in Fig. 8 and 9). The analysis revealed a ratio of $1: 2$ for the quantity of the MOF to the volume of the dye that afforded a suitable description of the adsorption process, as shown in Table 2 . This result indicates that the investigated MOFs are excellent materials for the removal of CR. CR is a cationic dye that exists in the form of positively charged ions in aqueous solutions (as shown in Fig. 7). The CR adsorption may not only result from simple physical adsorption and chemical adsorption but also form the conjugation between $\mathrm{CR}$ and MOFs. $\mathrm{CR}$ contains $\mathrm{C}=\mathrm{C}$ double bonds and $\pi$ electrons, and these $\pi$ electrons can easily interact 

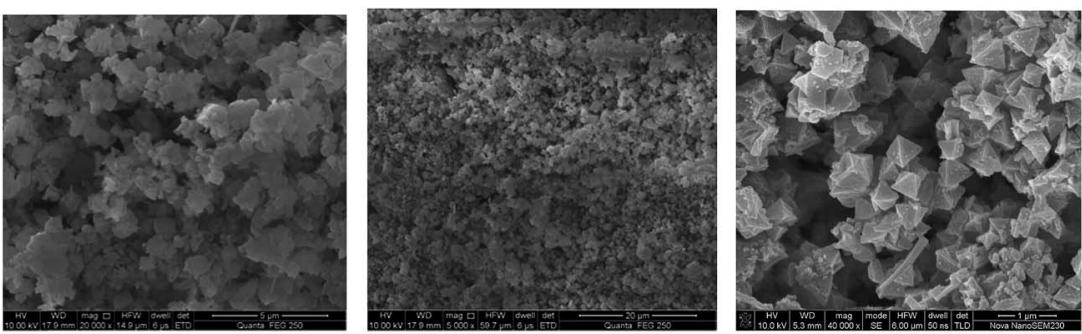

MOFs-1
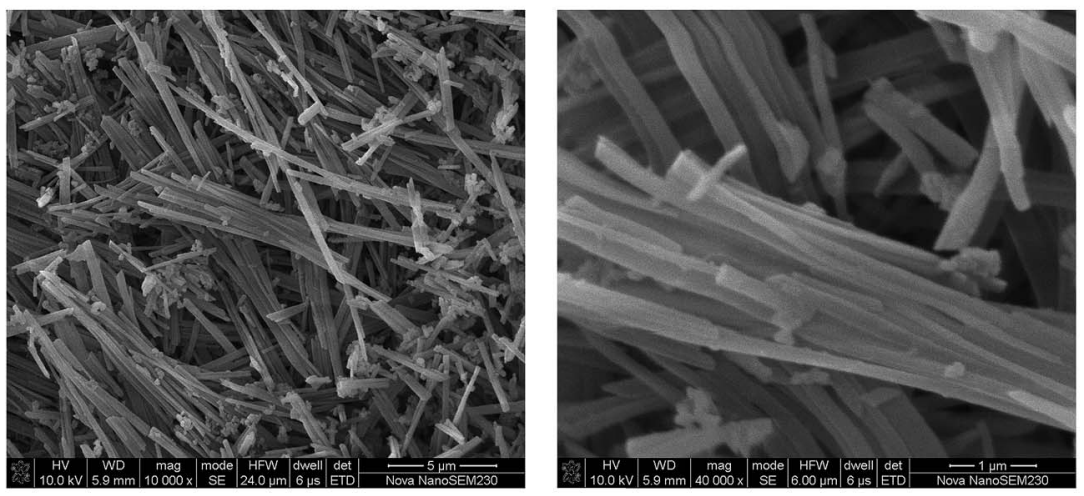

MOFs-2
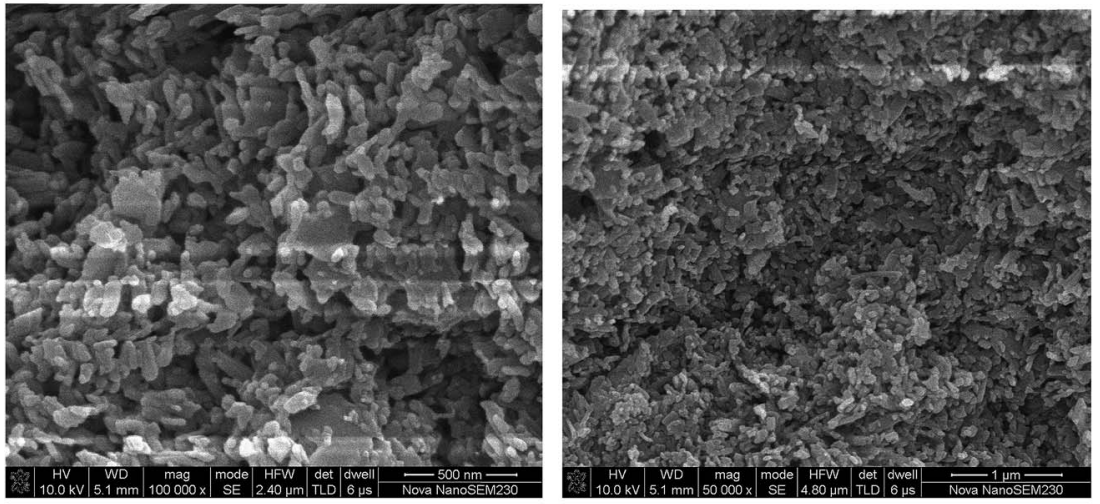

MOFs-3
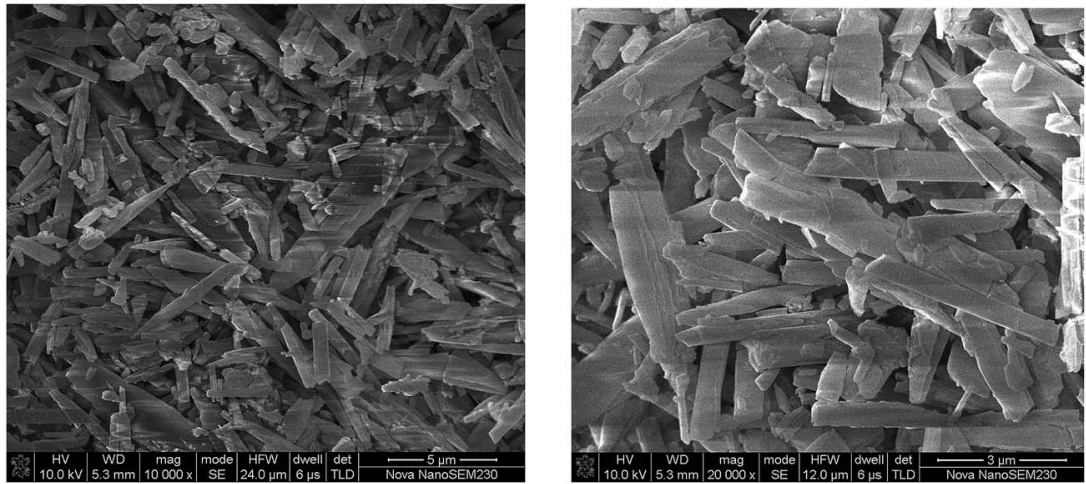

MOFs-4

Fig. 3 SEM images of MOFs.

with the $\pi$ electrons present on the benzene rings of the MOFs through $\pi-\pi$ interactions. CR could be adsorbed on the MOF surface with a face-to-face orientation by $\pi-\pi$ conjugation until an adsorption-desorption equilibrium is achieved. The
Zeta potential characterization showed that the adsorbents were charged, as shown in Table 3. Therefore, electrostatic forces are also beneficial for the adsorption of $\mathrm{CR}$ by the MOFs. ${ }^{54}$ 


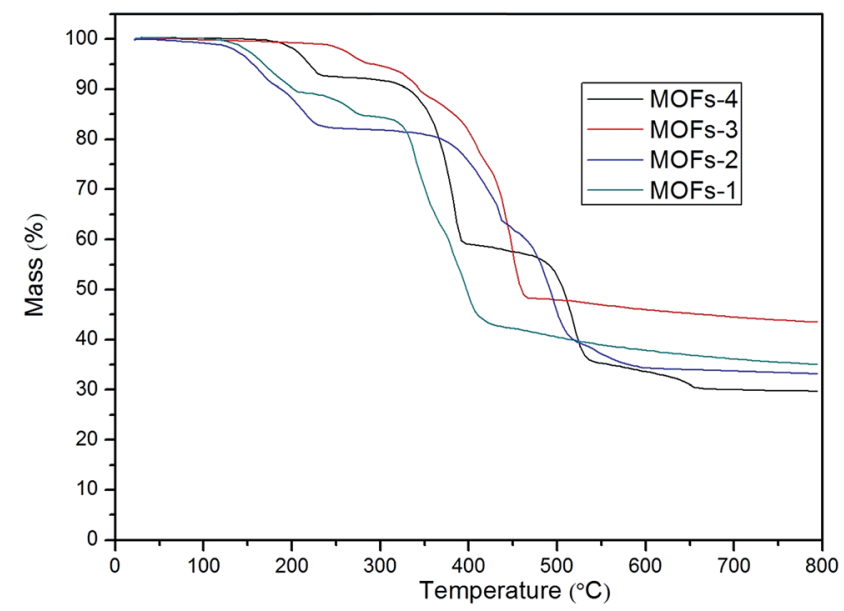

Fig. 4 TG curves for the four MOFs.

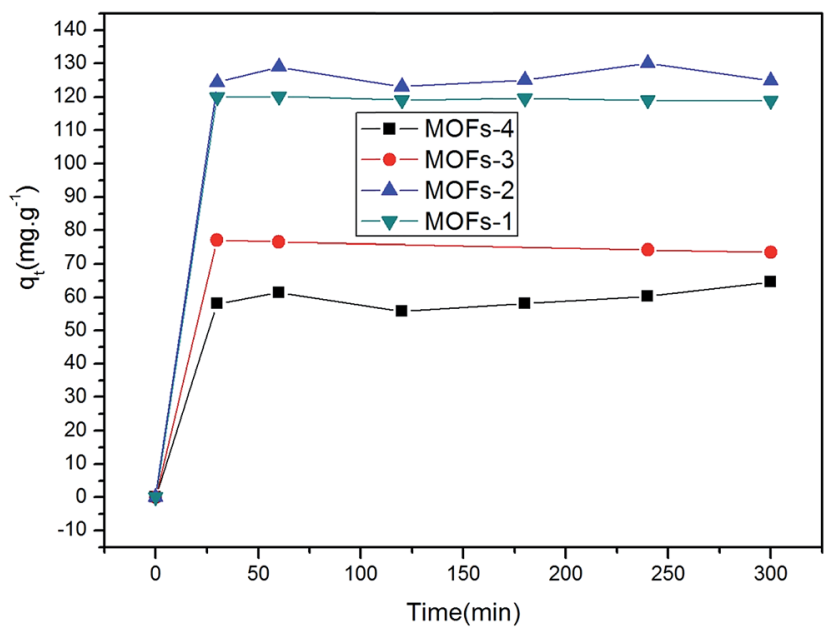

Fig. 5 Relationship between adsorbed quantities $\left(q_{t}\right)$ of CR and time.

\section{Experimental}

\section{Materials}

All materials were obtained from commercial suppliers and were used without further purification. 1,3,5-Benzenetricarboxylic acid (trimesic acid, $\mathrm{C}_{9} \mathrm{H}_{6} \mathrm{O}_{6}, \mathrm{H}_{3} \mathrm{BTC}, 98 \%$ ) and copper(II) acetate tetrahydrate $\left(\mathrm{Cu}\left(\mathrm{CH}_{3} \mathrm{COO}\right)_{2} \cdot 4 \mathrm{H}_{2} \mathrm{O}, \geq 99.0 \%\right)$ were purchased from Aladdin Biological Technology Co., Ltd., Shanghai, China. Terephthalic acid $\left(\mathrm{C}_{8} \mathrm{H}_{6} \mathrm{O}_{4}, \mathrm{H}_{2} \mathrm{BDC}, 99 \%\right)$ and cobalt(II) acetate tetrahydrate $\left(\mathrm{Co}\left(\mathrm{CH}_{3} \mathrm{COO}\right)_{2} \cdot 4 \mathrm{H}_{2} \mathrm{O}, \geq 99.5 \%\right)$ were purchased from Sinopharm Chemical Reagent Co., Ltd., Shanghai, China. Congo red (CR) was purchased from Aladdin Biological Technology Co., Ltd., Shanghai, China. Trimesic acid and terephthalic acid were used as organic linkers. Copper(II) acetate tetrahydrate and cobalt(II) acetate tetrahydrate were used as the metal ion sources in the synthesis of MOFs.

\section{Synthesis of MOFs}

Synthesis of MOF-1. Trimesic acid (5.0158 g, $0.0238 \mathrm{~mol})$, copper(II) acetate tetrahydrate $(3.2242 \mathrm{~g}, 0.0159 \mathrm{~mol})$, a stainless

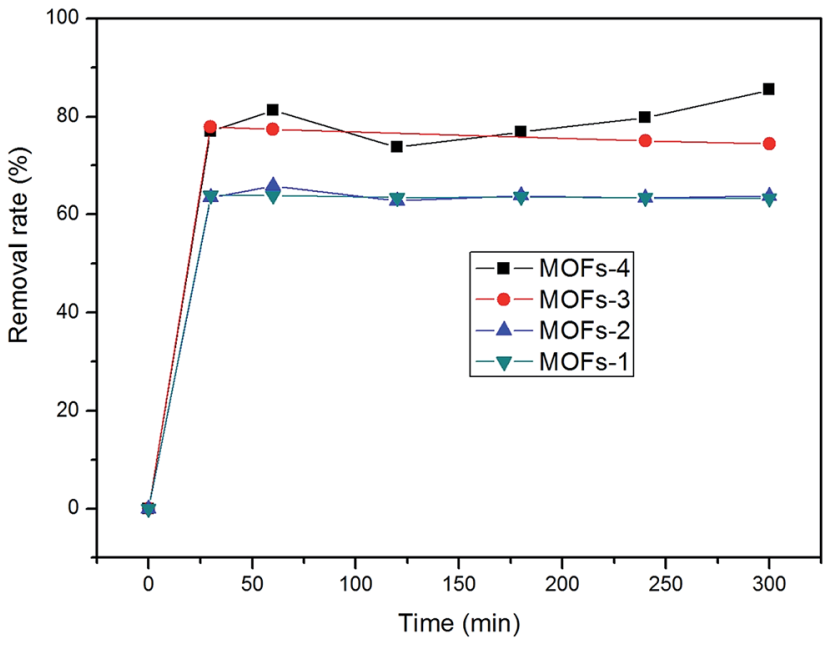

Fig. 6 Removal rate of MOFs.

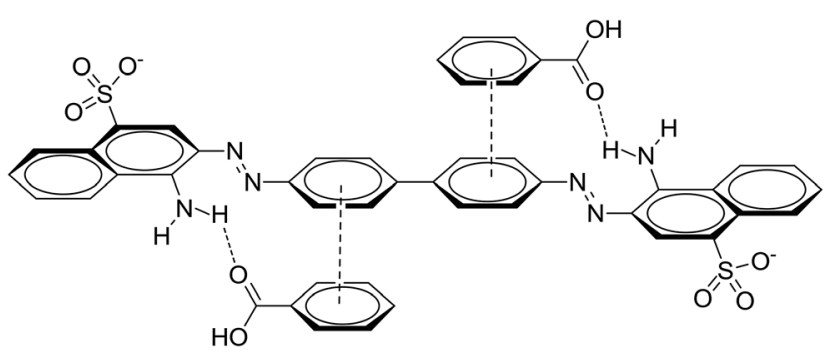

Fig. 7 Binding mechanism between CR and MOFs.

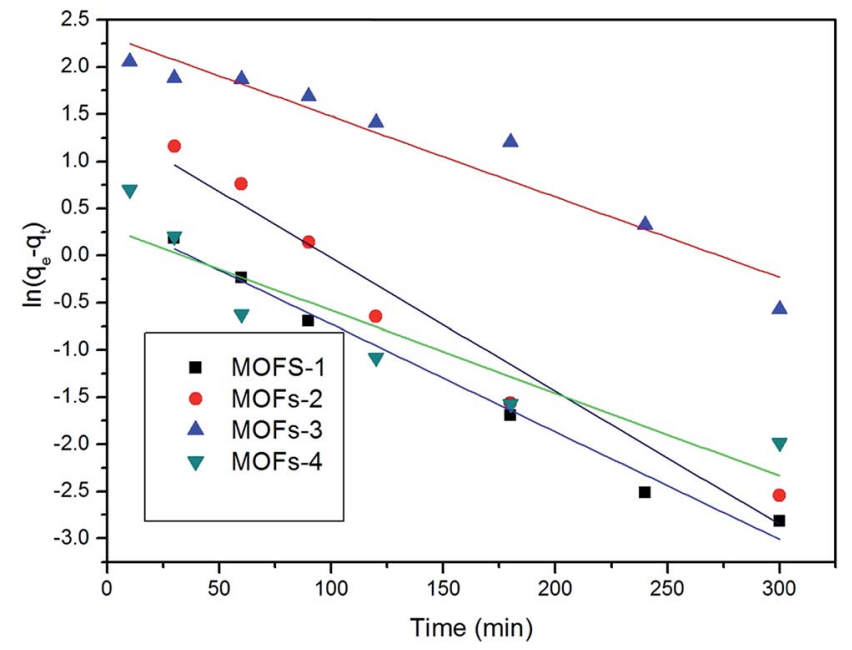

Fig. 8 Kinetic model of absorption when using 200 mg of MOFs.

steel ball (660 g), and $700 \mathrm{~mL}$ of deionized water were placed in a tetrafluoroethylene milling pot (diameter $140 \mathrm{~mm}$, height 90 $\mathrm{mm}$, volume $1.38 \mathrm{~L}$ ). Stir milling and microwave irradiation were introduced simultaneously with a constant stirring speed of $200 \mathrm{rpm}$. After $40 \mathrm{~min}$, the solution turned from colorless to blue and did not subsequently undergo any further changes in color. This change was accompanied by a significant evolution 


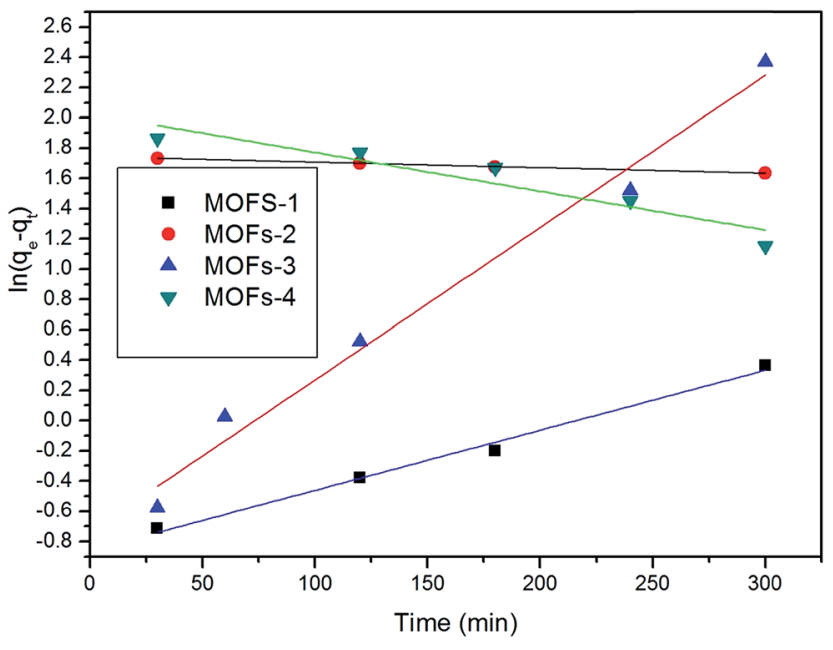

Fig. 9 Kinetic model of absorption when using $100 \mathrm{mg}$ of MOFs.

Table 2 Calculated kinetic parameters for pseudo-first-order models for the adsorption of CR using MOFs as adsorbents

\begin{tabular}{llllll}
\hline & \multicolumn{2}{l}{ Mass of MOFs $(200 \mathrm{mg})$} & & \multicolumn{2}{l}{ Mass of MOFs $(100 \mathrm{mg})$} \\
\cline { 2 - 3 } \cline { 5 - 6 } & $k$ & $R^{2}$ & & $k$ & $R^{2}$ \\
\hline MOFs-1 & -0.01143 & 0.98408 & & 0.00398 & 0.98814 \\
MOFs-2 & -0.01414 & 0.94257 & & -0.000364926 & 0.9986 \\
MOFs-3 & -0.00855 & 0.92131 & & 0.01007 & 0.9803 \\
MOFs-4 & -0.00878 & 0.82756 & & -0.00257 & 0.86008
\end{tabular}

of sour gas. The compound was filtered and washed with water. The filtered solid was added to a beaker with ethanol and stirred for $3 \mathrm{~h}$ using a magnetic stirrer. The precipitate was filtered under suction and dried. The final product was collected for subsequent characterization and experiments. The MOF-1 was obtained as a blue solid in $63.3 \%$ yield (based on copper(II) acetate tetrahydrate and trimesic acid).

Synthesis of MOF-2. The MOF-2 was prepared using the same procedure as described for MOF-1, starting from trimesic acid (5.0076 g, $0.0238 \mathrm{~mol})$, cobalt(II) acetate tetrahydrate $(3.9533 \mathrm{~g}, 0.0159 \mathrm{~mol})$, a stainless steel ball $(450 \mathrm{~g})$, and $700 \mathrm{~mL}$ of deionized water. After $40 \mathrm{~min}$ of reaction under the same conditions as stated above, the solution turned from colorless to damask, with no further changes in color observed subsequently. The color change was accompanied by a significant evolution of sour gas. The compound was filtered and washed with water. The filtered solid was added to a beaker with ethanol and stirred for $3 \mathrm{~h}$ using a magnetic stirrer. The precipitate was filtered under suction and dried. The final product was collected for subsequent characterization and absorption

Table 3 The Zeta potentials of the four MOFs

\begin{tabular}{lllll}
\hline & MOFs-1 & MOFs-2 & MOFs-3 & MOFs-4 \\
\hline Zeta potentials $(\mathrm{mV})$ & 208 & 413 & 316 & 339
\end{tabular}

experiments. The MOF-2 was obtained as a light red solid in $56.7 \%$ yield (based on cobalt(II) acetate tetrahydrate and trimesic acid).

Synthesis of MOF-3. This compound was synthesized using the same procedure as described for MOF-1 and MOF-2, commencing from terephthalic acid $(5.0101 \mathrm{~g}, 0.0301 \mathrm{~mol})$, copper(II) acetate tetrahydrate $(7.3593 \mathrm{~g}, 0.0370 \mathrm{~mol})$, a stainless steel ball ( $620 \mathrm{~g})$, and $700 \mathrm{~mL}$ of deionized water. After $40 \mathrm{~min}$ of reaction, the solution turned from colorless to blue. This change was accompanied by a significant evolution of sour gas. The compound was filtered and washed with water. The filtered solid was added to a beaker with ethanol and stirred for $3 \mathrm{~h}$ using a magnetic stirrer. The precipitate was filtered under suction and dried. The final product was collected for subsequent characterization and experiments. The MOF-3 was obtained as a blue solid in $62.47 \%$ yield (based on copper(II) acetate tetrahydrate and terephthalic acid).

Synthesis of MOF-4. This compound was synthesized using the same procedure as stated above for MOFs-1-3, starting from terephthalic acid $(5.0135 \mathrm{~g}, 0.0302 \mathrm{~mol})$, cobalt(II) acetate tetrahydrate $(7.6097 \mathrm{~g}, 0.0306 \mathrm{~mol})$, a stainless steel ball $(630 \mathrm{~g})$, and $700 \mathrm{~mL}$ of deionized water. After $40 \mathrm{~min}$ of reaction, the solution turned from colorless to damask color and this change was accompanied by a significant evolution of sour gas. The compound was filtered and washed with water. The filtered solid was added to a beaker with ethanol and stirred for $3 \mathrm{~h}$ using a magnetic stirrer. The precipitate was filtered under suction and dried. The final product was collected for subsequent characterization and experiments. The MOF- 4 was obtained as a light red solid in $\mathbf{4 4 . 7 \%}$ yield (based on cobalt(II) acetate tetrahydrate and terephthalic acid).

\section{Characterization of MOFs}

Structural and morphological characterizations were performed by XRD (D-5000, Siemens, Cu K $\alpha$ ), FTIR spectroscopy (IRTracer100; Shimadzu), and field-emission SEM (FESEM, JSM-6700F, Japan). Thermogravimetry (TG) curves of samples were recorded by a NETZSCH STA 449C thermal analyzer (Germany) in Ar atmosphere in the range from $0{ }^{\circ} \mathrm{C}$ to $800{ }^{\circ} \mathrm{C}$ at a heating rate of $5{ }^{\circ} \mathrm{C} \min ^{-1}$.

\section{Removal of Congo red}

Removal of Congo red was conducted at room temperature $(\sim 25$ ${ }^{\circ} \mathrm{C}$ ) in a $250 \mathrm{~mL}$ beaker. $50 \mathrm{mg}$ of a MOF sample was added to $200 \mathrm{~mL}$ of an organic dye solution $\left(\sim 50 \mathrm{mg} \mathrm{L}^{-1}\right)$, under natural light and magnetic stirring; every 10 to $30 \mathrm{~min}$, a $10 \mathrm{~mL}$ aliquot of the sample was analyzed by ultraviolet spectrometry (UV2550, 220 V, Shimadzu Instruments (Suzhou) Co., Ltd.). The removal rate was calculated by $C=\left(C_{0}-C_{t}\right) / C_{0} \times 100 \%$, where $C_{0}$ is the initial concentration and $C_{t}$ is the concentration of after $t$ minute.

\section{Conclusions}

In summary, the microwave-assisted ball milling approach was exploited successfully for the effective and reliable synthesis of 
four robust metal-organic frameworks, namely MOFs-1-4, in aqueous solutions, whose structures were confirmed by FTIR, XRD, SEM, and TGA. The MOFs showed good capacity to adsorb $\mathrm{CR}$, and could therefore be employed for the removal of CR from wastewater in the future. MOF-2-prepared from trimesic acid and cobalt(II) acetate tetrahydrate-exhibited the highest adsorption capacity for the removal of CR. These results demonstrate that the microwave-assisted ball milling process is an effective method for fast and simple preparation of MOFs for practical applications.

\section{Conflicts of interest}

There are no conflicts to declare.

\section{Acknowledgements}

The project was supported by Hunan Provincial Natural Science Foundation of China (14JJ1013) and the Joint Funds of Science and Technology Department of Guizhou Province with People's Government of Anshun City and Anshun University (LH [2016] 7268).

\section{References}

1 S. T. Meek, J. A. Greathouse and M. D. Allendorf, Adv. Mater., 2011, 23, 249.

2 S. Natarajan and P. Mahata, Chem. Soc. Rev., 2009, 38, 2304. 3 J. R. Long and O. M. Yaghi, Chem. Soc. Rev., 2009, 38, 1213. 4 W. Xia, A. Mahmood, R. Q. Zou and Q. Xu, Energy Environ. Sci., 2015, 8, 1837.

5 L. Wang, Y. Z. Han, X. Feng, J. W. Zhou, P. F. Qi and B. Wang, Coord. Chem. Rev., 2016, 307, 361.

6 B. Van de Voorde, B. Bueken, J. Denayer and D. De Vos, Chem. Soc. Rev., 2014, 43, 5766-5788.

7 J. R. Li, R. J. Kuppler and H.-C. Zhou, Chem. Soc. Rev., 2009, 38, 1477.

8 C. C. Wang, J. R. Li, X. L. Lv, Y. Q. Zhang and G. S. Guo, Energy Environ. Sci., 2014, 7, 2831.

9 J. Lee, O. K. Farha, J. Roverts, K. A. Schedit, S. T. Nguyen and J. T. Hupp, Chem. Soc. Rev., 2009, 38, 1450.

10 J. Della Rocca, D. M. Liu and W. B. Lin, Acc. Chem. Res., 2011, 44, 957.

11 C. Y. Sun, C. Qin, X. L. Wang and Z. M. Su, Expert Opin. Drug Delivery, 2013, 10, 89.

12 A. R. Millward and O. M. Yaghi, J. Am. Chem. Soc., 2005, 127, 17998.

13 K. Sumida, D. L. Rogow, J. A. Mason, T. M. McDonald, E. D. Bloch, Z. R. Herm, T. H. Bae and J. R. Long, Chem. Rev., 2012, 112, 724.

14 L. E. Kreno, K. Leong, O. K. Farha, M. Allendorf, R. P. Van Duyne and J. T. Hupp, Chem. Rev., 2012, 112, 1105.

15 H. Furukawa, K. E. Cordova, M. O'Keeffe and O. M. Yaghi, Science, 2013, 341, 974.

16 E. Barea, C. Montoro and J. A. R. Navarro, Chem. Soc. Rev., 2014, 43, 5419.
17 H. Wang, X. Z. Yuan, Y. Wu, G. M. Zeng, X. H. Chen, L. J. Leng, Z. B. Wu, L. B. Jiang and H. Li, J. Hazard. Mater., 2015, 286, 187.

18 R. W. Liang, F. F. Jing, L. J. Shen, N. Qin and L. Wu, J. Hazard. Mater., 2015, 287, 364.

19 Q. Q. Xu, H. J. Fan, Y. T. Li, K. E. Christensen and T. Z. Ren, Polyhedron, 2015, 92, 60.

20 E. Haque, J. W. Jun and S. H. Jhung, J. Hazard. Mater., 2011, 185, 507.

21 H. Wang, Appl. Catal., B, 2015, 174-175, 445.

22 N. A. P. Martins, C. P. Frizzo, D. N. Moreira, L. Buriol and P. Machado, Chem. Rev., 2009, 109, 4140.

23 B. Rodriguez, A. Bruckmann, T. Rantanen and C. Bolm, Adv. Synth. Catal., 2007, 349, 2213.

24 K. Tanaka, Solvent-free Organic Synthesis, Wiley-VCH, Weinheim, 2nd edn, 2008.

25 V. Sepelak, A. Düvel, M. Wilkening, K. D. Becker and P. Heitjans, Chem. Soc. Rev., 2013, 42, 7507.

26 A. L. Garay, A. Pichon and S. L. James, Chem. Soc. Rev., 2007, 36, 846.

27 P. Balaz, M. Achimovicova, M. Balaz, P. Billik, Z. CherkezovaZheleva, J. M. Criado, F. Delogu, E. Dutkova, E. Gaffet, F. J. Gotor, R. Kumar, I. Mitov, T. Rojac, M. Senna, A. Streletskii and K. Wieczorek-Ciurowa, Chem. Soc. Rev., 2013, 42, 7571.

28 S. L. James, C. J. Adams, C. Bolm, D. Braga, P. Collier, T. Friscic, F. Grepioni, K. D. M. Harris, G. Hyett, W. Jones, A. Krebs, J. Mack, L. Maini, A. G. Orpen, I. P. Parkin, W. C. Shearouse, J. W.Steed and D. C. Waddelli, Chem. Soc. Rev., 2012, 41, 413.

29 T. Friscic, Chem. Soc. Rev., 2012, 41, 3493.

30 A. Pichon and S. L. James, CrystEngComm, 2008, 10, 1839.

31 W. Yuan, T. Friscic, D. Apperley and S. L. James, Angew. Chem., Int. Ed., 2010, 49, 3916.

32 J. Huot, D. B. Ravnsb, J. Zhang, F. Cuevas, M. Latroche and T. R. Jensen, Prog. Mater. Sci., 2013, 58, 30.

33 P. Niu and J. Hao, Langmuir, 2011, 27, 13590.

34 S. Pal, S. Ghorai, C. Das, S. Samrat, A. Ghosh and A. B. Panda, Ind. Eng. Chem. Res., 2012, 51, 15546.

35 X. X. Wang, B. y. Yu, K. V. Hecke and G. H. Cui, RSC Adv., 2014, 4, 61281.

36 J. M. Hu, V. A. Blatov, B. y. Yu, K. V. Hecke and G. H. Cui, Dalton Trans., 2016, 45, 2426.

37 J. W. Cui, W. J. An, K. V. Hecke and G. H. Cui, Dalton Trans., 2016, 45, 17474.

38 M. Y. Masoomi, M. Bagheri and A. Morsali, Ultrason. Sonochem., 2016, 33, 60.

39 S. Q. Zhao, D. Chen, F. H. Wei, N. N. Chen, Z. Liang and Y. Luo, Ultrason. Sonochem., 2017, 39, 845.

40 C. Racles, M.-F. Zaltariov, M. Iacob, M. Silion, M. Avadanei and A. Bargan, Appl. Catal., B, 2017, 205, 78.

41 B. Y. Chen, D. Chen, Z. T. Kang and Y. Z. Zhang, J. Alloys Compd., 2015, 618, 222.

42 D. Chen, Y. Z. Zhang and Z. T. Kang, Chem. Eng. J., 2013, 215, 235.

43 D. Chen, Y. Z. Zhang and C. J. Tu, Mater. Lett., 2012, 82, 10. 
44 D. Chen, Y. Z. Zhang, B. Y. Chen and Z. T. Kang, Ind. Eng. Chem. Res., 2013, 52, 14179.

45 G. Chen, Z. Song, J. Chen and J. H. Peng, J. Alloys Compd., 2013, 579, 612.

46 Y. Z. Zhang, Z. T. Kang and D. Chen, Mater. Lett., 2014, 133, 259.

47 G. Chen, J. Alloys Compd., 2015, 651, 503.

48 ed. R. H. Crabtree, The Organometallic Chemistry of the Transition Metals, 5th edn, 2012, p. 148.

49 ed. H.-w. Zhu, Spectral analysis of organic molecular structure, Chemical Industry Press, Beijing, 2010, p. 54.
50 A. Alec Talin, A. Centrone, A. C. Ford, M. E. Foster, V. Stavila, P. Haney, R. Adam Kinney, V. Szalai, F. El Gabaly, H. P. Yoon, F. Léonard and M. D. Allendorf, Science, 2014, 343, 66.

51 N. Stock and S. Biswas, Chem. Rev., 2012, 112, 933.

52 X. Zhao, S. Liu, Z. Tang, H. Niu, Y. Cai, W. Meng, F. Wu and J. P. Giesy, Sci. Rep., 2015, 5, 11849.

53 C. Li, Z. Xiong, J. Zhang and C. Wu, J. Chem. Eng. Data, 2015, 60, 3414.

54 T. Wu, X. Cai, S. Tan, H. Li, J. Liu and W. Yang, Chem. Eng. J., 2011, 173, 144.

55 R. Liang, L. Shen, F. Jing, W. Wu, N. Qin, R. Lin and L. Wu, Appl. Catal., B, 2015, 162, 245. 